\title{
Multicenter Evaluation of an ELISA for the Detection of Cryptosporidium spp. Antigen in Clinical Human Stool Samples
}

\author{
Romy Razakandrainibe ${ }^{1,2, *}$, Célia Mérat ${ }^{3}$, Nathalie Kapel ${ }^{4}$, Marc Sautour ${ }^{5}$, Karine Guyot ${ }^{6}$, Gilles Gargala ${ }^{1,2}$, \\ Jean-Jacques Ballet ${ }^{1}$, Patrice Le Pape ${ }^{3}$ (D), French Cryptosporidiosis Network ${ }^{\dagger}$, Frédéric Dalle ${ }^{5,7}$ \\ and Loïc Favennec 1,2,*
}

Citation: Razakandrainibe, R.; Mérat C.; Kapel, N.; Sautour, M.; Guyot, K.; Gargala, G.; Ballet, J.-J.; Le Pape, P.; French Cryptosporidiosis Network; Dalle, F; et al. Multicenter Evaluation of an ELISA for the Detection of Cryptosporidium spp. Antigen in Clinical Human Stool Samples. Microorganisms 2021, 9, 209. https://doi.org/10.3390/ microorganisms 9020209

Academic Editor: Juan Carlos Gutiérrez

Received: 29 December 2020

Accepted: 14 January 2021

Published: 20 January 2021

Publisher's Note: MDPI stays neutral with regard to jurisdictional claims in published maps and institutional affiliations.

Copyright: (c) 2021 by the authors. Licensee MDPI, Basel, Switzerland. This article is an open access article distributed under the terms and conditions of the Creative Commons Attribution (CC BY) license (https:// creativecommons.org/licenses/by/ $4.0 /)$.
1 EA ESCAPE 7510, University of Medicine Pharmacy Rouen, 76000 Rouen, France; gilles.gargala@chu-rouen.fr (G.G.); balletjeanj@laposte.net (J.-J.B.)

2 CNR LE Cryptosporidiosis, Santé Publique France, 76000 Rouen, France

3 Department of Parasitology/Mycology, University Hospital of Nantes, 44093 Nantes, France; celia.merat@chu-nantes.fr (C.M.); patrice.lepape@chu-nantes.fr (P.L.P.)

4 Department of Parasitology/Mycology, Faculty of Pharmacy, Paris University, 75013 Paris, France; nathalie.kapel@aphp.fr

5 Department of Parasitology/Mycology, University Hospital of Dijon, 21000 Dijon, France; marc.sautour@chu-dijon.fr (M.S.); frederic.dalle@chu-dijon.fr (F.D.)

6 Department of Parasitology/Mycology, Lille Pasteur Institute, 59000 Lille, France; karine.guyot@pasteur-lille.fr

7 CNR LE Cryptosporidiosis Collaborating Laboratory, Santé Publique France, 21000 Dijon, France

* Correspondence: romy.razakandrainibe@univ-rouen.fr (R.R.); loic.favennec@chu-rouen.fr (L.F.); Tel.: +33-2-35-14-86-55 (R.R.); +33-2-32-88-14-55 (L.F.)

+ French Cryptosporidiosis Network are list in the Appendix A.

Abstract: Human cryptosporidiosis remains underdiagnosed, and rapid/accurate diagnosis is of clinical importance. Diagnosis of the Cryptosporidium oocyst in stool samples by conventional microscopy is labor-intensive, time-consuming, and requires skillful experience. Thus, we aimed to evaluate the usefulness of a coproantigen enzyme-linked immunosorbent assay (ELISA) test in detecting Cryptosporidium spp. from fecal specimens. For this aim, we evaluated the performances of a commercial ELISA (CoproELISA Cryptosporidium kit, Savyon Diagnostics, Israel) for the detection of Cryptosporidium spp. in random clinical stool samples through a multicenter study. The sensitivity and specificity for coproantigen ELISA were $98.86 \%$ and $94.32 \%$, respectively. The coproantigen ELISA results indicate that the simple, rapid, reliable, and standardized immunoassay test is sensitive and specific for routine diagnosis, and may be useful for large-scale epidemiological studies of cryptosporidiosis.

Keywords: cryptosporidiosis; Cryptosporidium spp.; diagnosis; coproantigen ELISA; largescale epidemiology

\section{Introduction}

Cryptosporidiosis, an emerging infectious disease of public health significance worldwide, is caused by the protozoan Cryptosporidium. Currently, twenty-three species and 61 valid genotypes of Cryptosporidium spp. have been described from a wide range of vertebrates, including humans, mammals, wildlife, domestic livestock, reptile, birds, amphibians, and fish, causing asymptomatic or mild-to-severe gastrointestinal disease in its host species [1].

Cryptosporidium parvum and the anthroponotic Cryptosporidium hominis are the major causes of human cryptosporidiosis. Although infection is asymptomatic, sometimes it causes diarrhea with a large number of oocysts present in the stools, as the acute infection resolves and the patient becomes asymptomatic, the number of oocysts decreases. Cryptosporidium can also cause chronic diarrhea, abdominal pain, weakness, weight loss, 
which can result in death in immunosuppressed individuals [2,3]. The diagnosis of cryptosporidiosis is usually made by microscopic detection of the parasite oocysts. However, this method is labor-intensive, time-consuming, requires skillful experience, and has low sensitivity [4,5]. Molecular biology techniques have become diagnostic tools that have been used to understand the epidemiology of Cryptosporidium spp. However, the accessibility to this technique is limited in some laboratories and totally absent in others. In addition, the expense and requirement for technical expertise have limited their use, particularly in high-prevalence regions, such as developing countries.

Enzyme immunoassay (EIA) for detecting antigen has been introduced successfully for Cryptosporidium screening in feces [5,6] Demonstration of cryptosporidial antigen in stool using ELISA is useful for screening large numbers of specimens. Several commercial immunochromatographic assays are currently available; however, previous comparisons have revealed limitations in their sensitivities according to Cryptosporidium species [7]. Potential advantages of commercially available ELISA kits for coproantigens are thus standardization of reagents, potential automatable process, and reproducibility in the context of administrative validation procedures. However discrepant data are available concerning this method [8].

The aim of the present study is to evaluate the performances of a commercial ELISA (CoproELISA Cryptosporidium kit, Savyon Diagnostics, Israel) for the detection of Cryptosporidium spp. in random clinical stool samples through a multicenter study.

\section{Materials and Methods}

The study was conducted in three medical parasitology laboratories from the University Hospitals of Rouen (Lab\#1), Nantes (Lab\#2), and Dijon (Lab\#3) with recognized proficiency in the detection of Cryptosporidium spp.

Fifty stool samples containing Cryptosporidium oocysts were provided by the French Cryptosporidium National Network [9] and separately investigated by Lab\#1 and Lab\#2.

In addition, 12 and 28 fresh C. parvum oocyst-positive random samples were assayed separately by Lab\#1 and Lab\#3, respectively. The diagnosis was established by microscopy, and then the Cryptosporidium species determined by PCR sequencing at the $18 \mathrm{~S}$ ribosomal DNA locus [10] which consisted of C. parvum $(n=20)$, C. hominis $(n=20)$, C. felis $(n=6)$, C. meleagridis $(n=2), C$. canis $(n=1)$, and an C. chipmunk $(n=1)$. Each study center was also provided with 56 (Lab\#1), 60 (Lab\#2) and 60 (Lab\#3) potassium dichromate fixed $\left(\mathrm{K}_{2} \mathrm{Cr}_{2} \mathrm{O}_{7}\right.$ PBS) negative controls in which the absence of Cryptosporidium spp. was screened by microscopy. Secondly all negative controls were studied by PCR.

Cyclospora and Cystoisospora oocysts' strong autofluorescence properties render fluorescence microscopy useful for identification [11]. In epifluorescence microscopic examination, using a 330-380-nm ultraviolet filter, C. cayetanensis oocysts can be easily visible in clinical samples [12]. Oocysts of Cystoisospora can be differentiated by their roundish appearance, their thin, smooth wall and, after sporulation, by the number of sporocysts [13]. None of the samples contained other Coccidia, i.e., Cyclospora or Cystoisospora.

To assess human clinical stool preservation's effects on the CoproELISA performance, we used five fresh stool samples with C. parvum oocyst counts ranging from 4 to 76 per 50 microscopic fields (MF).

For each stool, four conditions were studied, i.e., undiluted stool, 1:10 stool dilution in PBS, 1:1 stool dilution in $2.5 \%$ potassium chromate (K2CRO4), PBS, and undiluted stool kept frozen at $\left(-80^{\circ} \mathrm{C}\right)$ for $\geq 48 \mathrm{~h}$.

In each laboratory, ELISA were performed in triplicates according to the manufacturer's instructions (Savyon Diagnostics, Ashrod, Israel) by the same experienced staff member to minimize handling risks and reading errors. The Cryptosporidium antigen negative and positive internal control preparations were provided by the manufacturer. Results were expressed as absolute 450/605 nm 3,3',5,5'-Tetramethylbenzidine (TMB) product optical density (OD) values. Stool samples were considered ELISA-positive when the corresponding mean $\mathrm{OD}$ value was $\geq$ to the mean Cryptosporidium negative internal sample 
OD + 0.300 OD. Optical density of positive internal controls was checked for each series of experiments.

The sensitivities, specificities, positive predictive values and negative predictive values were calculated according to Loong [14].

\subsection{Intra-Assay (Test-Retest) Assay}

Intra-assay variability was investigated sequentially on the same day with one ELISAnegative and 2 ELISA-positive clinical stool samples diluted 1:10 in PBS (one sample containing C. paroum oocysts and 1 containing C. chipmunk genotype oocysts). For each sample, 6 independent ELISA were performed in triplicates (different plates, same reagents).

\subsection{Inter-Assay ELISA Reproducibility}

The replicate (inter-assay) ELISA reproducibility was assessed using one ELISAnegative sample and one ELISA-positive sample (containing C. hominis oocysts), tested independently in triplicates on 4 different days.

\subsection{Statistical Evaluation of Results}

Contingency analysis was performed using exact Fisher's test. Distribution comparisons between series of results were performed using $t$ tests, thus assuming normal-like distribution of data. Correlation trends were estimated by calculating r correlation coefficient values.

\section{Results and Discussion}

3.1. Effects of Human Clinical Stool Preservation on Cryptosporidium spp. Antigen ELISA Detection

Most available clinical samples being preserved in $\mathrm{K} 2 \mathrm{CRO} 4$ and/or frozen buffers, preliminary experiments were aimed at evaluating the effects of K2CRO4 treatment and freezing on ELISA antigen detection. As shown in Table 1, no difference in OD values was observed between undiluted stool, 1:10 stool dilution in PBS, 1:1 stool dilution in $2.5 \% \mathrm{~K} 2 \mathrm{CRO} 4 \mathrm{PBS}$, and undiluted stool kept frozen at $\left(-80^{\circ} \mathrm{C}\right)(p>0.05)$. Specifically, all samples were found antigen positive.

Table 1. Influence of PBS dilution, $\mathrm{K}_{2} \mathrm{Cr}_{2} \mathrm{O}_{7}$ addition and freezing of Cryptosporidium oocyst-positive samples on ELISA optical density (OD) values.

\begin{tabular}{|c|c|c|c|c|}
\hline Stool Sample \# & Undiluted & $\begin{array}{c}\text { 1:10 Dilution in } \\
\text { PBS }\end{array}$ & $\begin{array}{l}\text { 1:1 Dilution in } 2.5 \% \\
\mathrm{~K}_{2} \mathrm{Cr}_{2} \mathrm{O}_{7} \mathrm{PBS}\end{array}$ & Frozen $\left(-80^{\circ} \mathrm{C}\right)$ \\
\hline 1 & 4.407 & 4.345 & 4.242 & 4.030 \\
\hline 2 & 4.296 & 4.249 & 4.294 & 4.328 \\
\hline 3 & 4.399 & 4.258 & 4.325 & 4.600 \\
\hline 4 & 4.333 & 3.690 & 4.416 & 4.474 \\
\hline 5 & 4.471 & 4.443 & 4.292 & 4.325 \\
\hline
\end{tabular}

Results expressed as 405/605 nm mean OD values of triplicates. The coefficient of variation (CV), which is the measure of relative variability; the ratio of the standard deviation (SD) to the mean, accounted for less than $10 \%$. \#: sample number.

\subsection{Intra-Assay Variability and Inter-Assay ELISA Reproducibility}

For the intra-assay, the mean OD $( \pm S D)$ were $0.326( \pm 0.032) ; 1.210( \pm 0.108)$ and 4.108 $( \pm 0.385)$ for oocyst-negative, and stools with C. paroum and C. chipmunk oocyst, respectively, corresponding to a coefficient of variation lower than $10 \%$ for experimental samples. The ELISA reproducibility resulted in mean OD $0.329( \pm 0.034)$ and $3.600( \pm 0.231)$, respectively.

3.3. Influence of Cryptosporidium spp. oocyst Concentration in Clinical Stools on ELISA Antigen Detection

ELISA detection cut-off value for clinical samples was estimated in a pilot study according to C. parvum oocyst counts in stools. As shown in Table 2, OD exhibited moderate variation (from 3.690 to 4.407 ) from $<1$ oocyst to 76 oocysts $/ 50 \mathrm{MF}$, which suggests that 
ELISA may detect antigens in clinical samples containing very low oocyst concentrations and considered microscopically negative.

Table 2. Influence of stool oocyst concentration on ELISA antigen detection.

\begin{tabular}{ccccc}
\hline Sample \# & $\begin{array}{c}\text { Oocyst Concentration in } \\
\text { Undiluted Stool (Number/50 MF) }\end{array}$ & OD & $\begin{array}{c}\text { Oocyst Concentration in 1/10 PBS } \\
\text { Diluted Stool (Number/50 MF) }\end{array}$ & OD \\
\hline 1 & 76 & 4.407 & 13 & 4.345 \\
2 & 23 & 4.296 & 6 & 4.249 \\
3 & 17 & 4.471 & 4 & NA \\
4 & $5-10$ & 2.743 & NA & NA \\
5 & $5-10$ & 4.375 & 1 & 4.258 \\
6 & 6 & 4.399 & $<1$ & 3.690 \\
\hline
\end{tabular}

Results expressed as 405/605 nm mean OD values of triplicates. The coefficient of variation accounted for less than $10 \%$. \#: sample number; MF: microscopic fields; NA: non-available.

3.4. Inter-Laboratory Evaluation of ELISA Sensitivity and Species Specificity for Cryptosporidium spp. Oocyst-Positive Random Clinical Samples

For 50 oocyst-positive stools separately investigated by Lab\#1 and Lab\#2 (Table 3), close OD values were obtained by the two laboratories (ranges 0.199-4.420, and 0.1845.327, means OD ( $\pm \mathrm{SD}): 3.952( \pm 1.620)$ and 3.572 $( \pm 1.303)$, in Lab\#1 and Lab\#2, respectively, $\mathrm{r}=0.93)$. Mean cut-off values were $0.496( \pm 0.021)$ and $0.480( \pm 0.051)$, for Lab\#1 and Lab\#2, respectively. Close mean OD values were obtained for the 20 C. parvum and the $20 \mathrm{C}$. hominis oocyst-positive stools $(4.319( \pm 0.792)$ and $3.772( \pm 0.146)$, respectively, $p>0.05)$. All Samples with $C$. felis, $C$ chipmunk, C. meleagridis and $C$. canis sample were ELISA positive in both laboratories. Identical decisions on ELISA positivity/negativity were obtained for all samples with $2 / 50$ exceptions, i.e., one $C$. hominis-PCR positive sample, for which cutoff values (0.474 and 0.594, respectively) resulted in discrepant negative and positive conclusion, respectively. Two C. cuniculus-PCR positive samples exhibited low OD and were considered negative by both laboratories.

Table 3. Summary of ELISA results for Cryptosporidium spp. oocyst positive stool samples.

\begin{tabular}{cccccc}
\hline & $\begin{array}{c}\text { Lab\#1 ELISA } \\
\text { Positive Samples }\end{array}$ & $\begin{array}{c}\text { Lab\#2 ELISA } \\
\text { Positive Samples }\end{array}$ & $\begin{array}{c}\text { Labs \#1 and \#2 Consensus } \\
\text { ELISA Results }\end{array}$ & $\begin{array}{c}\text { Lab\#3 } \\
\begin{array}{c}\text { Lab\#1: Additional } \\
\text { Positive Samples }\end{array}\end{array} \quad \begin{array}{c}\text { Oocyst and ELISA } \\
\text { Positive Samples }\end{array}$ \\
\hline ELISA Positive $(\mathrm{n})$ & 49 & 47 & 47 & 28 & 12 \\
\hline Total $(\mathrm{n})$ & 50 & 50 & 48 & 28 & 12 \\
\hline
\end{tabular}

All 12 stool Cryptosporidium parvum-PCR positive samples studied separately by Lab\#1 were ELISA positive (mean OD 3.470 \pm 1.201 , mean cut-off OD $0.462 \pm 0.034$ ). For 28 C. parvum PCR-positive random samples examined by Lab\#3, OD ranged from 0.800 to 4.060 (mean cut off $0.650 \pm 0.035)$, and all were considered ELISA-positive.

As summarized in Table 4, ELISA detection of Cryptosporidium spp. antigens in 176 oocyst-negative clinical samples resulted in 166 true negative and 10 false-positive results

Table 4. Summary of ELISA results for Cryptosporidium spp. oocyst negative samples.

\begin{tabular}{ccccc}
\hline & Lab\#1 & Lab\#2 & Lab\#3 & Total \\
\hline ELISA negative & 50 & 59 & 57 & 166 \\
\hline ELISA positive & 6 & 1 & 3 & 10 \\
\hline Total & 56 & 60 & 60 & 176 \\
\hline
\end{tabular}

Among the negative controls, 6 and 1 were found ELISA-positive (OD range: 0.671-3.549) by Lab\#1 and Lab\#2, respectively. In Lab\#1, $4 / 6$ samples were controlled negative by microscopic examination, but positive by PCR. The false-positive sample found by Lab\#2 was positive for strongyloides stercoralis. At first, it was suspected cross-contamination between 
Cryptosporidium and nematode antigens, but this was ruled out as Strongyloides stercoralis ova found in few other samples were negative with the ELISA. Lab\#3 found three false-positive samples that, after microscopy and PCR control, turn out to be negative to Cryptosporidium. No other intestinal parasites were found during this control.

\section{Conclusions}

In summary, ELISA detection of Cryptosporidium spp. coproantigens performed in 88 oocyst microscopy-positive clinical samples and 176 microscopy-negative samples resulted in 87 true positive, a false negative, 166 true negative, and 10 false negative results in at least one lab leading to sensitivity, specificity, positive and negative predictive value of $98.86 \%, 94.32 \%, 89.69 \%$, and $99.40 \%$, respectively. These data show that the method is efficient to identify Cryptosporidium oocysts in stool samples whatever the species with the exception of C. cuniculus, which seems to give lower OD values, but this result has to be confirmed as few samples were evaluated. Interestingly, the quantity of oocysts did not interfere with the result as sample with few or many oocysts were detected with similar OD values as previously described [8].

Coproantigen detection using ELISA method requires minimal training thus appeared to be easy to perform, as well as accurate for epidemiological studies and diagnostic purposes of Cryptosporidium infection, compared with conventional microscopic methods.

Author Contributions: Conceptualization, R.R. and L.F.; methodology, L.F., C.M., N.K., M.S., K.G., G.G.; validation, L.F., P.L.P. and F.D.; formal analysis, L.F., R.R.; investigation, L.F.; data curation, R.R.; writing—original draft preparation, R.R., J.-J.B.; writing—review and editing, R.R., J.-J.B., L.F.; supervision, L.F. All members of the French Cryptosporidiosis Network have provided isolates used in this study. All authors have read and agreed to the published version of the manuscript.

Funding: This research was supported by the French cryptosporidiosis National Reference Center under grant MIG F14 CNR.

Institutional Review Board Statement: Not applicable.

Informed Consent Statement: Not applicable.

Data Availability Statement: Not applicable.

Conflicts of Interest: The authors declare no conflict of interest.

\section{Appendix A}

French Cryptosporidiosis Network

Isabelle Accoceberry, Adela Angoulvant, Nicolas Argy, Dominique Aubert, Patrick Bastien, Ghania Belkadi, Antoine Berry, Denis Blanchet, Julie Bonhomme, Françoise Botterel, Marie Elizabeth Bougnoux, Julie Brunet, Gabriela Certad, Cathy Chemla, Eric Dannaoui, Marie Laure Darde, Anne Debourgogne, Luc de Gentile, Brigitte Degeilh, Pascal Delaunay, Nicole Desbois, Guillaume Desoubeaux, Pierre Flori, Emilie Frealle, Cécile Garnaud, Frédéric Grenouillet, Samia Hamane, Sandrine Houze, Franck. Labbé, Denis Leméteil, Coralie Lollivier, Yohann Le Govic, Denis Magne, Pierre Marty, Jean Menotti, Florent Morio, Gilles Nevez, Muriel Nicolas, Philippe Poirier, Christelle Pomares, Meja Rabodonirina, Florence Robert Gangneux, Marie Hélène Rodier, Milene Sasso, Marc Thellier, Anne Totet, Stéphane Valot, Odile Villard, Isabelle Villena, Hélène Yera.

\section{References}

1. Ryan, U.; Fayer, R.; Xiao, L. Cryptosporidium Species in Humans and Animals: Current Understanding and Research Needs. Parasitology 2014, 141, 1667-1685. [CrossRef] [PubMed]

2. Dillingham, R.A.; Lima, A.A.; Guerrant, R.L. Cryptosporidiosis: Epidemiology and Impact. Microbes Infect. 2002, 4, 1059-1066. [CrossRef]

3. Khurana, S.; Chaudhary, P. Laboratory Diagnosis of Cryptosporidiosis. Trop. Parasitol. 2018, 8, 2. [CrossRef] [PubMed]

4. Vanathy, K.; Parija, S.C.; Mandal, J.; Hamide, A.; Krishnamurthy, S. Detection of Cryptosporidium in Stool Samples of Immunocompromised Patients. Trop. Parasitol. 2017, 7, 41-46. [CrossRef] [PubMed] 
5. Garcia, L.S.; Shimizu, R.Y.; Bernard, C.N. Detection of Giardia Lamblia, Entamoeba Histolytica/Entamoeba Dispar, and Cryptosporidium Parvum Antigens in Human Fecal Specimens Using the Triage Parasite Panel Enzyme Immunoassay. J. Clin. Microbiol. 2000, 38, 3337-3340. [CrossRef] [PubMed]

6. Garcia, L.S.; Shimizu, R.Y. Evaluation of Nine Immunoassay Kits (Enzyme Immunoassay and Direct Fluorescence) for Detection of Giardia Lamblia and Cryptosporidium Parvum in Human Fecal Specimens. J. Clin. Microbiol. 1997, 35, 1526-1529. [CrossRef] [PubMed]

7. Agnamey, P.; Sarfati, C.; Pinel, C.; Rabodoniriina, M.; Kapel, N.; Dutoit, E.; Garnaud, C.; Diouf, M.; Garin, J.-F.; Totet, A.; et al. Evaluation of Four Commercial Rapid Immunochromatographic Assays for Detection of Cryptosporidium Antigens in Stool Samples: A Blind Multicenter Trial. J. Clin. Microbiol. 2011, 49, 1605-1607. [CrossRef] [PubMed]

8. Sadaka, H.A.; Gaafar, M.R.; Mady, R.F.; Hezema, N.N. Evaluation of ImmunoCard STAT Test and ELISA versus Light Microscopy in Diagnosis of Giardiasis and Cryptosporidiosis. Parasitol. Res. 2015, 114, 2853-2863. [CrossRef] [PubMed]

9. ANOFEL Cryptosporidium National Network. Laboratory-Based Surveillance for Cryptosporidium in France, 2006-2009. Euro Surveill. Bull. Eur. Sur Mal. Transm. Eur. Commun. Dis. Bull. 2010, 15, 19642.

10. Xiao, L.; Escalante, L.; Yang, C.; Sulaiman, I.; Escalante, A.A.; Montali, R.J.; Fayer, R.; Lal, A.A. Phylogenetic Analysis of CryptosporidiumParasites Based on the Small-Subunit RRNA Gene Locus. Appl. Environ. Microbiol. 1999, 65, 1578-1583. [CrossRef] [PubMed]

11. Garcia, L.S.; Arrowood, M.; Kokoskin, E.; Paltridge, G.P.; Pillai, D.R.; Procop, G.W.; Ryan, N.; Shimizu, R.Y.; Visvesvara, G. Practical Guidance for Clinical Microbiology Laboratories: Laboratory Diagnosis of Parasites from the Gastrointestinal Tract. Clin. Microbiol. Rev. 2018, 31, e00025-17. [CrossRef] [PubMed]

12. Eberhard, M.L.; Pieniazek, N.J.; Arrowood, M.J. Laboratory Diagnosis of Cyclospora Infections. Arch. Pathol. Lab. Med. 1997, 121, 792-797. [PubMed]

13. Joachim, A.; Ruttkowski, B.; Sperling, D. Detection of Cystoisospora Suis in Faeces of Suckling Piglets-When and How? A Comparison of Methods. Porc. Health Manag. 2018, 4, 20. [CrossRef] [PubMed]

14. Loong, T.-W. Understanding Sensitivity and Specificity with the Right Side of the Brain. BMJ 2003, 327, 716-719. [CrossRef] [PubMed] 